\title{
Chromosome Abnormalities in Two Cases with Bilateral Radial Element Defects
}

\author{
MICHAEL FAED, ANN STEWART, ${ }^{\star}$ and A. J. KEAY \\ From the Medical Research Council, Clinical and Population Cytogenetics Research Unit, Western General Hospital, \\ Edinburgh; and Northern Group of Hospitals, Edinburgh
}

Hypoplasia of the radial elements has been reported in a number of conditions associated with chromosomal abnormalities. In particular, the defect is frequent in cases with Fanconi's anaemia (Nilsson, 1960); it has been found in cases of the trisomy-E syndrome (Zellweger, Huff, and Abbo, 1965), and Sparkes, Carrel, and Wright (1967) have proposed a syndrome in which the absence of thumbs is associated with deletion of material from a chromosome in the D group.

We have found evidence of chromosome instability in two patients with bilateral radial element defects. There was a large ring chromosome in cells from fibroblast cultures obtained from an infant with bilateral absence of the radius and thumb, transposition of the great arteries, and other congenital abnormalities, and there were two or three different cell lines in addition to normal female cells in cultures from an adult with hypoplastic thumbs and an atrial septal defect.

\section{Case Reports}

Case 1. This male infant was the second child of healthy non-consanguineous parents, the father being 32 years and the mother 26 years at the birth. The older male sib is 5 years and healthy. The mother's sister died at the age of 1 year with gastro-enteritis, otitis media, and a persistent ductus arteriosus. The father is an only child.

Foetal movements were first reported at an estimated 23 weeks of gestation, and an $x$-ray at 37 weeks suggested development compatible with 30 weeks' gestation, confirming clinical evidence of slow foetal growth. Pregnancy terminated spontaneously after 43 weeks of gestation. At birth the child's condition was very poor and he only lived 7 minutes in spite of vigorous attempts at resuscitation. He weighed $1480 \mathrm{~g}$. There was gross peeling of the skin, bilateral cleft lip, and complete cleft palate, bilateral epicanthic folds, flat occiput with webbed neck, and small flat ears. The scrotum was

\footnotetext{
Received March 3, 1969.

* Present address: M.R.C. Human Biochemical Genetics Research Unit, University College, London.
}

small and empty. No testes could be palpated in the groin or perineum. There was absence of the radius 0 and thumb on both sides, and the hands were long and $\dot{\sigma}$ narrow without transverse palmar creases. The palm $\dot{\omega}$ prints were poor and difficult to assess, but the left index and middle fingers carried ulnar loops and there may $N$ have been a whorl on digit IV. On the right hand, 을 digits II, III, and IV all carried ulnar loops. The lower $\vec{C}$ limbs were normal. At necropsy the only additional of finding was an enlarged heart with transposition of the great arteries.

Case 2. This female, aged 34, was referred to us because of mongoloid facies noted during investigation of cyanotic congenital heart disease which had been recogo nized at birth but not investigated at that time. She is said to have been born prematurely and to have weighed about $900 \mathrm{~g}$. $(2 \mathrm{lb}$.). When aged 2 years her thumb were amputated because they were malformed and hindered the useful function of her hands. She is of low intellect, and capable of simple domestic duties only. Before surgical repair of her atrial septal defect she was deeply cyanosed at all times and had intermittent syncopal attacks. Her height is $146 \mathrm{~cm}$. She has epicanthus and a flattened occiput, bilateral absence of thumbs and thenar eminences, with a small linear scar over the second metacarpal bones and clinodactyly of both 5 th fingers. On $x$-ray, she has complete absence of both thumbs and first metacarpals with hypoplastic scaphoids. The distal phalanges are long and tapering. The position of the ' $t$ ' triradius and associated patterns on palm prints confirms the rudimentary nature of the thumbs (Fig. 1).

\section{Cytogenetics}

In Case 1 mosaicism (45,XY,B - /46,XY/46,XY,Br) was found in each of two independently derived fibroblast cultures from the skin when these were examined one month after the cultures had been established. The dominant line had a large ring chromosome replacing one of the B group (Fig. 2 and Fig. 3a). The ring did not appear to vary in size though a few cells were present in which an abnormal chromosome replaced the ring (Fig. 3b, c), and cells with two rings were also found. Normal male cells and cells with 45 chromosomes entirely lacking a member of the $B$ group represented the other cell types. The numerical distribution of the cell 
types is shown in Table I. After prolonged subculture the large ring disappeared and was replaced by a smaller ring (Fig. 3d), and in these older cultures cells with 45 chromosomes lacking a $\mathbf{B}$ group chromosome were not
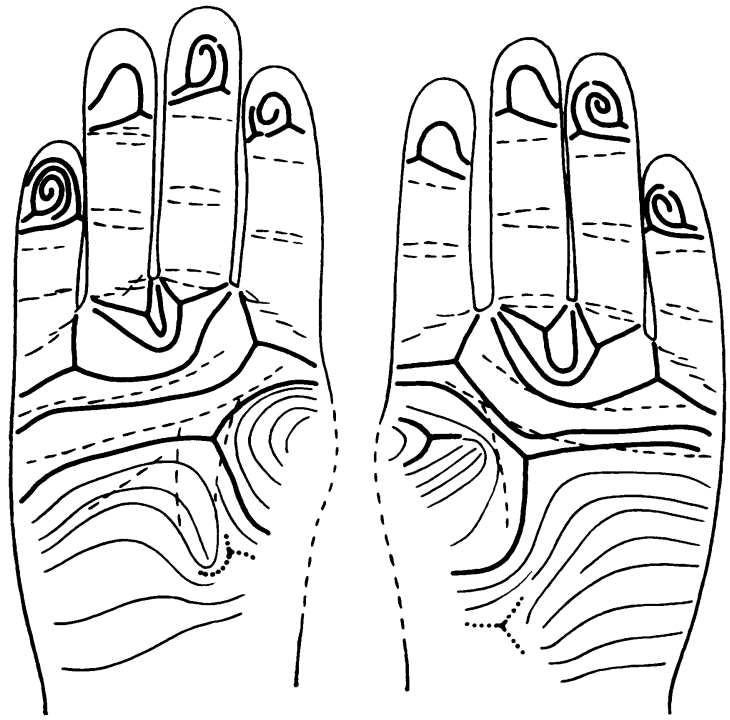

Fig. 1. Dermatoglyphic patterns of the hands of Case 2. present. It was not possible to examine the chromosomes of cells of the peripheral blood. The chromosomes of the parents appeared to be normal.

Case 2 was found to have normal female cells in the peripheral blood but a mosaic $(46, \mathrm{XX} / 46, \mathrm{XX}, \mathrm{C}+, \mathrm{D}-$, $\mathrm{G}-, \operatorname{mar}+/ 47, \mathrm{XX}, \mathrm{G}+$ ) pattern in one fibroblast culture from her skin. In a culture from a second biopsy taken on a subsequent occasion from a different site, there were no cells with the marker chromosome though cells with an additional $G$ chromosome were present. There were also few cells with an additional mediumsized chromosome. The marker chromosome in the first culture appears to be the result of a translocation in which long arm material from a D or G group chromosome was transferred to the short arms of a $G$ or a $D$ group chromosome (Fig. 4). The numerical distribution of each cell type is shown in Table II.

\section{Discussion}

Though the abnormalities are different in degree, both of these cases have a bilateral radial element defect and an abnormality of cardiac development. Cardiac abnormalities are frequently associated with radial element defects and largely account for the poor prognosis for patients with such defects (Birch-Jensen, 1949). Attempts have even been made to recognize syndromes with specific heart

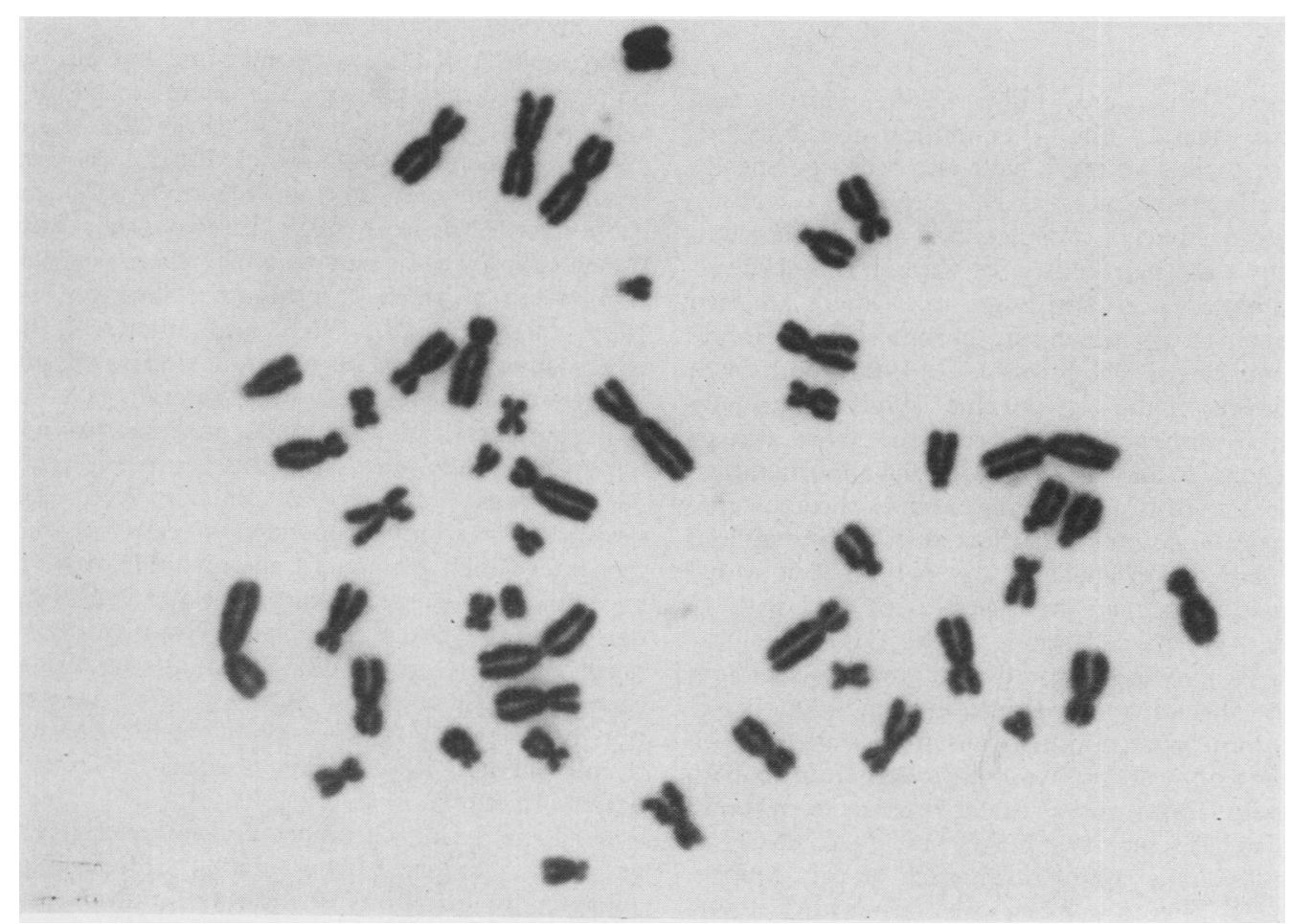

FIG. 2. Case 1. Cell with ring chromosome. 


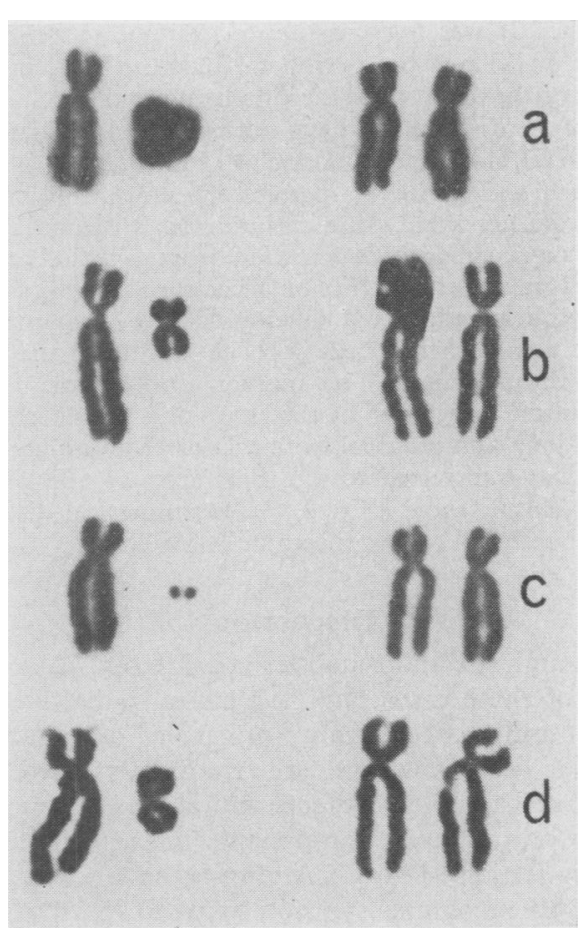

Fig. 3. Case 1. B-group chromosomes from four cells. a-c, early cultures; $d$, late culture.

disorders (Holt and Oram, 1960; Harris and Osborne, 1966). The other clinical abnormalities found in these two cases have not been specifically associated with radial aplasias.

Both cases have a chromosomal abnormality in a proportion of their cells. In Case 1 the chromosome affected is in the $B$ group. There are two other reports of similar ring chromosomes (Rohde and Tompkins, 1965; Steele et al., 1966): both cases were typical of the 'cri du chat' syndrome usually associated with a deletion from the short arm of chromosome 5, and neither had radial abnormalities. In Case 2 one cell line has an extra $G$ chromosome, and its presence may be reflected in the mongoloid facies and low intellect of the patient, but radial absence defects have not been associated with $G$ trisomy. In the cell line with the $D / G$ translocation there may be chromosomal material missing from the short arm of a D chromosome. A ring D chromosome was found in cells from a foetus with an absent right and a hypoplastic left thumb (Bain and Gauld, 1963), and a similar ring has been found by others (Adams, 1965; Sparkes et al., 1967) in association with complete absence of the thumbs. In these, as in both our cases, the upper limb abnormality was bilateral and restricted to the radial
TABLE I

NUMBERS OF EACH CELL TYPE IN TWO INDEPENDENTLY DERIVED FIBROBLAST CULTURES IN CASE 1

\begin{tabular}{|c|c|c|c|}
\hline B Group Abnormality & Culture A & Culture B & Total \\
\hline \multirow{2}{*}{$\begin{array}{l}\text { None } \\
-\mathbf{B},+ \text { large ring } \\
-\mathbf{B},+ \text { other } \\
\text { abnormal chromosomes } \\
-\mathbf{B}\end{array}$} & $\begin{array}{r}2 \\
14\end{array}$ & $\begin{array}{r}12 \\
9\end{array}$ & $\begin{array}{l}14 \\
23\end{array}$ \\
\hline & $\begin{array}{l}5 \\
9\end{array}$ & $\begin{array}{l}1 \\
8\end{array}$ & $\begin{array}{r}6 \\
17\end{array}$ \\
\hline Total cells & 30 & 30 & 60 \\
\hline
\end{tabular}

TABLE II

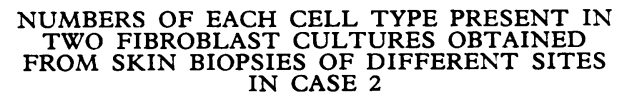

\begin{tabular}{|c|c|c|c|}
\hline Karyotype & Culture A & Culture B & Total \\
\hline $\begin{array}{l}46, \mathrm{XX} \\
47, \mathrm{XX}, \mathrm{G}+ \\
46, \mathrm{XX}, \mathrm{C}+, \mathrm{D}-, \mathrm{G}-, \mathrm{mar}+ \\
47, \mathrm{XX}, \mathrm{C}+\end{array}$ & $\begin{array}{r}18 \\
4 \\
8 \\
-\end{array}$ & $\begin{array}{r}25 \\
1 \\
3\end{array}$ & $\begin{array}{r}43 \\
5 \\
8 \\
3\end{array}$ \\
\hline Total cells & 30 & 29 & 59 \\
\hline
\end{tabular}

elements; there was also a cardiac abnormality and a low birthweight. It has been suggested that this syndrome results from deletion of material from a $\mathrm{DB}$ chromosome (Sparkes et al., 1967).

Hypoplasia of the radial elements has also been reported in a few cases of the complete trisomysyndrome, though in most of these the anomaly affected only the left limb (Kajii, 1967). A recently reported case was affected bilaterally (GonzalesRamos and Ahedo, 1968). In two other cases a translocation was present in which there was partial duplication of an $\mathrm{E}$ chromosome (Gagnon et al., 1963; Oikawa et al., 1963), and in one of these, which involved loss of material from a B group chromosome, the anomaly was bilateral.

In patients with Fanconi's anaemia, in which hypoplasia of the radial elements is present in about $34 \%$ of cases (Nilsson, 1960), cultures from various tissues show a high proportion of cells with chromosomes which are structurally unstable, though no specific chromosome appears to be affected (Schroeder, Anschütz, and Knopp, 1964; Swift and Hirschhorn, 1966). Chromosome instability has also been reported in the cells of a child with growth retardation and congenital dislocation of the hip and absent thumbs but without pancytopenia (Varela and Sternberg, 1967).

Autosomal ring chromosomes are relatively rare and all are theoretically unstable. There is good evidence for instability of the ring found in Case 1. In Case 2, though there is no evidence for persistent 


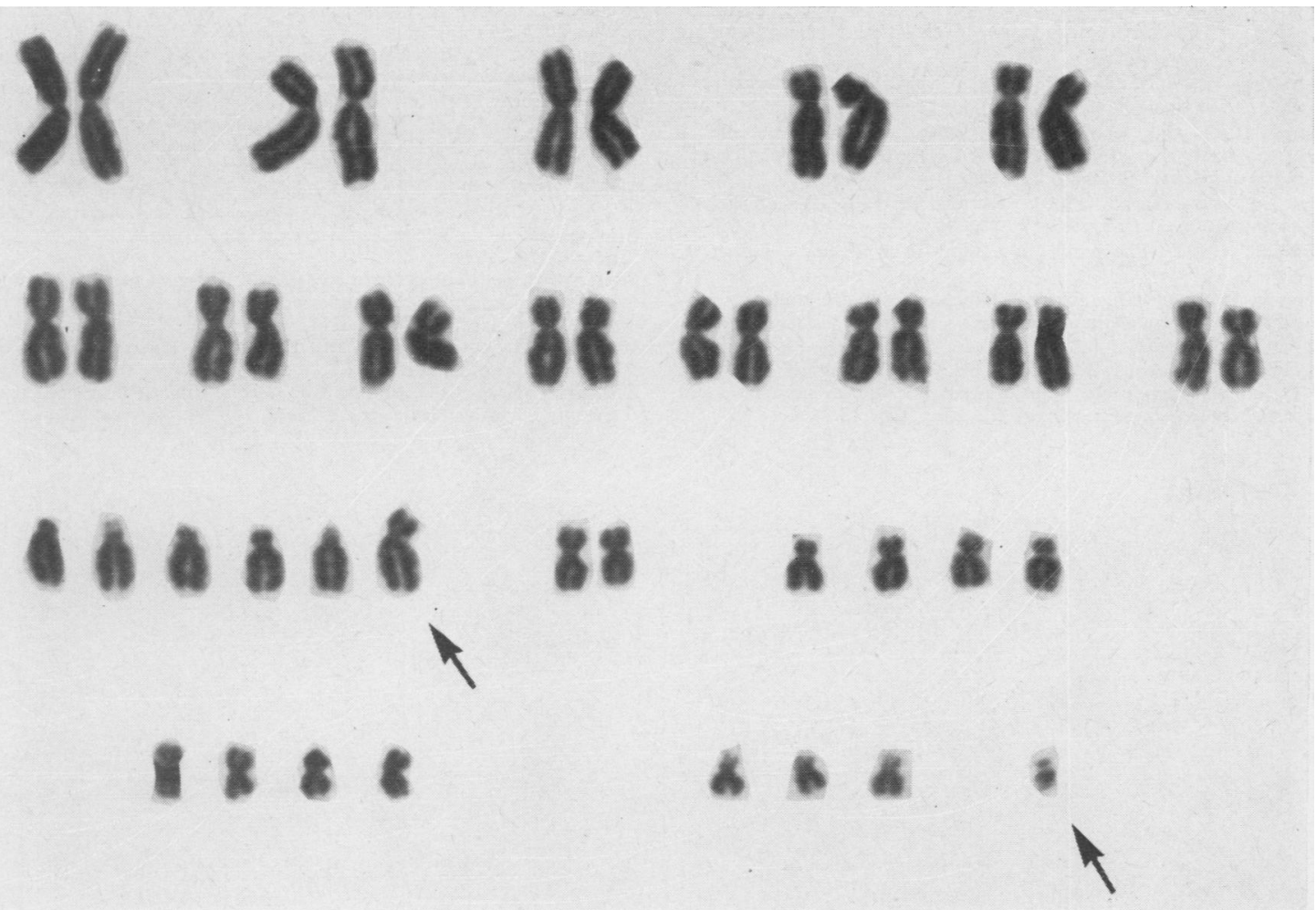

FIG. 4. Case 2. Karyotype of cell with D/G translocation.

instability, the presence of two, and possibly three, abnormal cell lines as well as a normal one indicates a considerable disturbance of chromosome stability at some point in time. It does seem to be significant that, apart from those cases associated with trisomy-E, instability is such a feature of the chromosome abnormalities found in the cells of individuals with radial element absence defects. Chromosome instability, by increasing the rate of cell loss, may not only reduce the over-all rate of growth and affect the birthweight, but also differentially affect the development of specific structures or organs which depend particularly on a wellordered rate of cellular multiplication. The result will clearly depend on the proportion of cells carrying unstable chromosomes and the degree of this instability.

\section{Summary}

Two cases with an association of bilateral radial element hypoplasia, cardiac anomaly, and low birthweight were found to have cells with an abnormal chromosome complement. The chromosome abnormality affected different chromosomes in the 8 two cases. In one there was a large B-ring chromosome which was unstable in vitro, and in the other two or three different abnormalities were found in different cells suggesting chromosome instability. Unstable chromosomes have been found in other cases with radial abnormalities, and it may be this feature, rather than a specific genetic abnormality, which is responsible for the hypoplasia as well as for the poor over-all growth.

We wish to thank Dr. R. M. Marquis for referring Case 2 to us and Dr. W. Price for a clinical report on this patient; Dr. A. D. Bain for the necropsy of Case 1 ; Professor L. S. Penrose for reporting on the palm prints of both patients; and Dr. Patricia Jacobs for the results of the peripheral blood chromosome studies. We are also grateful for the technical assistance of Mrs. Margaret Black.

\section{REFERENCES}

Adams, M. S. (1965). Palm-prints and a ring-D chromosome. Lancet, 2, 494.

Bain, A. D., and Gauld, I. K. (1963). Multiple congenital abnormalities associated with ring chromosome. ibid., $2,304$.

Birch-Jensen, A. (1949). Congenital Deformities of the Upper Extremities. Andelsbog Erykkeriet, Odense. 
Gagnon, J., Archambault, L., Laberge, E., and Katyk-Longtin, N. (1963). Trisomic partielle 18 par insertion ou translocation $4 / 18$. Un. méd. Can., 92, 311.

Gonzales-Ramos, M., and Ahedo, M. A. (1968). A new human trisomy? Lancet, 2, 680 .

Harris, L. C., and Osborne, W. P. (1966). Congenital absence or hypoplasia of the radius with ventricular septal defect. Ventriculoradial dysplasia. F. Pediat., 68, 265.

Holt, M., and Oram, S. (1960). Familial heart disease with skeletal malformations. Brit. Heart f., 22, 236.

Kajii, T. (1967). Phocomelia in trisomy-18 syndrome. Lancet, 1, 385.

Nilsson, L. R. (1960). Chronic pancytopenia with multiple congenital abnormalities (Fanconi's anaemia). Acta paediat. (Uppsala), 49, 518.

Oikawa, K., Kochen, J. A., Schorr, J. B., and Hirschhorn, K. (1963). Trisomy-17 syndrome with phocomelia due to complete and partial chromosomal trisomy. f. Pediat., 63, 715.
Rohde, R. A., and Tompkins, R. (1965). 'Cri du chat' due to a $§$ ring-B (5) chromosome. Lancet, 2, 1075.

Schroeder, T. M., Anschütz, F., and Knopp, A. (1964). Spontane (D Chromosomen-aberrationen bei familiärer Panmyelopathie. $\overparen{(\mathbb{D}}$ Hum. Genet., 1, 194.

Sparkes, R. S., Carrel, R. E., and Wright, S. W. (1967). Absent $\overrightarrow{=}$ thumbs with a ring $\mathrm{D}_{2}$ chromosome. A new deletion syndrome. Amer. F. hum. Genet., 19, 644.

Steele, M. W., Breg, W. R., Eidelman, A. I., Lion, D. T., and Terzakis, T. A. (1966). A B-group ring chromosome with mosaicism in a newborn with cri du chat syndrome. Cytogene- $\bar{\omega}$ tics, 5, 419.

Swift, M. R., and Hirschhorn, K. (1966). Fanconi's anaemia. In- $Q$ herited susceptibility to chromosome breakage in various tissues. Ann. intern. Med., 65, 496.

Varela, M. A., and Sternberg, W. H. (1967). Preanaemic state in Fanconi's anaemia. Lancet, 2, 566.

Zellweger, H., Huff, D. S., and Abbo, G. (1965). Phocomelia and trisomy E. Acta Genet. med. (Roma), 14, 164. 